\title{
Problems of the of health-saving environment at the engineering university
}

\author{
Elvira Mugattarova ${ }^{1 *[0000-0001-9897-226 X]}$, Anatoly Bolotnikov ${ }^{1}$, Rais Imangulov $^{1}$, Vladimir Kalmanovich ${ }^{1}$, \\ and Rafael Khairullin ${ }^{1}$
}

${ }^{1}$ Kazan State University of Architecture and Engineering, 420043 Kazan, Russia

\begin{abstract}
The article deals with the issues of health-saving of students at Kazan State University of Architecture and Engineering. It identifies problems and possible ways to solve them in the health-saving environment of the university. To obtain information, a SWOT analysis of the organization of this environment was conducted, the degree of prevention, maintenance and preservation of students' health at the technical university in the process of training future specialists in full-time training, as well as distance learning in the context of a pandemic was determined. «Problem Solving and Decision-Making» (PSDM) method was used, in the process of which possible solutions to the problems of the development of chronic fatigue and emotional burnout syndromes in architecture students in the course of full-time training and deterioration of the health of university students in the course of distance learning were identified. The method of psychological and pedagogical diagnostics was applied - testing in an online format, as a result of which the problems of health saving in the process of distance learning were identified. Methods of solving these problems were found (universal exercises were used in the conditions of limited home space).

Keywords. Health-saving environment, distance learning, students, Engineering University.
\end{abstract}

\section{Introduction}

At present, future specialists are subject to high requirements for the level of proficiency in professional skills, knowledge, abilities, intellectual, personal, and physical development, which together are the main tasks of the modern education system [1]. As a result, in the preparation of a modern specialist, integrity becomes relevant, expressed in the following objective indicators: active performance (in any environmental conditions), socialization (professional and labor), high moral qualities, as well as awareness of the need to preserve health. An essential factor determining the state of health is the maintenance of optimal physical activity and health-saving throughout life [2]. Health-saving is an essential dynamic characteristic of the process of life activity of an individual, characterized by the presence of knowledge, skills and abilities necessary for the implementation of health-saving activities and determining the priorities of the individual in the educational society [3].

\footnotetext{
*Corresponding author: asan611@yandex.ru
} 
The national doctrine of education in the Russian Federation clearly defines that the state in education is obliged to establish as a priority and the highest social value the provision of comprehensive care for the health of school children and students. The education of young people should form a responsible attitude to their own health and others [4].

At the university, the process of forming a health-preserving environment is fulfilled on the basis of the interrelated practical activities of all participants in the educational process (management, teachers, students):

The work of the administrative management of the university is focused on the following steps:

a) organization of effective functioning of all subjects of the educational process;

b) formation of extremely comfortable conditions for joint activities of teachers and students;

c) implementation of control and correction of issues on health-saving work at the university.

The work of scientific and teaching staff is focused on the adaptation and implementation of health-saving technologies in their subject of study.

In a health-saving educational environment, students' work is focused on preserving their own health, developing value orientations aimed at maintaining health-saving in the process of study.

The structure and essence of the health-saving educational environment of the university can be considered as a set of factors (material, pedagogical, psychological), functionally related, ordered components of the activities of its subjects, interacting with each other, in order to achieve certain results in health-saving at the university.

\section{Materials and methods}

The purpose of this study is to identify the factors of the formation of a health-saving environment of a technical university in the conditions of traditional (teacher-student contact in the classroom) and distance education to preserve the health of students.

Objectives of the study: to identify the level (strengths and weaknesses) of the formation of a health-saving environment of a technical university; to determine practical actions to solve the problems of organizing the educational process in full-time training and distance learning.

To achieve this goal, we used the following research methods: SWOT analysis of the organization of this environment, the PSDM method which presents psychological and pedagogical diagnostics-testing in online format.

\section{Results}

The main role in the organization of the educational process is played by a well-organized health-saving environment of the university. In the process of studying this environment, the following results were obtained using the following methods:

\subsection{Swot - analysis}

To determine the level of formation of the health-saving environment of the university in the 2018-2019 academic years, we used a universal, convenient method of strategic planning (SWOT analysis - determination of strong, weak directions of development, external threats) [5], and established the following results:

- the university's strong health-saving direction - active use of health-saving technologies in the educational process: medical and hygienic technologies, measures to ensure the safety of life, health-saving educational technologies, organization of an environmentally safe external environment of the university, as well as active conduct of physical training and recreation activities (the university was awarded the following titles: 2015 «The most sports organization in the republican branch of education»; 2017 «The best 
university of the Republic of Tatarstan for the production of mass sports and recreation and sports work»; 2018 Winner of the All-Russian review-competition «For the best organization of sports and recreation work among educational organizations of higher education») [6].

- the weak side of health saving at the university is a consequence of the influence of external factors (external threats), and the aggravation of these problems during the training of students of the Institute of Architecture and Design (IAD) - a constant state of stress during the session and continuous design, which in turn causes deterioration in the state of health and development of chronic fatigue syndrome (CFS) - neurological disease manifests itself with psychoemotional stress in the process of multitasking, is expressed in constant fatigue that does not stop after a long rest. This fact is aggravated by provoking factors: unbalanced intellectual, emotional stress to the detriment of physical activity [7, 8]. Against the background of physical and mental exhaustion, emotional burnout syndrome (EBS) can develop. The condition characterized by increasing emotional exhaustion, manifested in indifference to everything around, to dehumanization, to dissatisfaction with their studies, future profession, which in turn causes the development of various diseases caused by psychosomatics $[9,10]$.

\section{2 «Problem Solving \& Decision Making» Method (PSDM)}

To solve the existing and possibly future problems in the formation of a health-saving environment of the university in the context of a pandemic and distance learning, we used the PSDM method - «Problem Solving and Decision-Making», during which possible solutions to the problems were identified. The problems are as follows - the development of chronic fatigue syndromes and emotional burnout of architecture students during full-time training; - deterioration of the health of university students during distance learning.

To prevent the development of chronic fatigue syndrome and emotional burnout syndrome in architecture students in the course of full-time training, work began on collecting materials for a methodological guidance, which established methods and principles for using health-saving technologies in the educational process, as well as defined rules for a healthy lifestyle. To overcome the unbalanced academic load in the process of intellectual activity more gently, in the process of physical education at physical training classes, students of architecture were given to study complexes of health systems consisting of adapted mental fitness exercises to perform at the school site [11].

In the spring semester of the 2019-2020 academic years, against the backdrop of a global pandemic, we determined that another weakness in the university's health-preserving environment is the prevention of deterioration of health and the preservation of the health of students in the process of distance learning.

To prevent the spread of COVID-19 in Russian universities, the Ministry of Science and Higher Education of the Russian Federation has prescribed new rules for the organization of educational activities (order of 14.03.2020) - to introduce individual holidays for students, to conduct distance learning until the epidemiological situation improves [12]. In these conditions, the issue of organizing and conducting independent physical education classes for university students during self-isolation has become acute [13-15].

To overcome the health problems experienced by students of all Kazan State University of Architecture and Engineering institutes on distance learning in isolation, we applied the practice of overcoming chronic fatigue syndromes and emotional burnout for students of the Institute of Architecture and Design:

- the methodological guidance previously prepared for students of architecture was supplemented, in which, in addition to the principles, rules, and methods of maintaining a healthy lifestyle during the educational process, exercises of various fitness programs for the development of endurance, strength, and flexibility in conditions of self-isolation and limited space were added to the complexes of mental fitness $[16,17]$; 
- in remote physical education classes, in order to overcome unbalanced intellectual, emotional, and physical activity, all students were trained in special sets of exercises from health-improving systems at the training place at the computer and in the conditions of a limited space of an apartment or house for more effective training of the entire muscular corset and relieving psychoemotional tension $[18,19]$.

\subsection{The method of psychological and pedagogical diagnostics using testing}

To determine the problems of health saving in the process of full-time and distance learning, online testing of students of Kazan State University of Architecture and Engineering using Google Forms was conducted. The total number of participants is 1066 people, including by gender: girls $57.6 \%$ (614), boys 42.4\% (452); course of study: 1 - 31,9\% (340), $2-35,6 \%$ (380), $3-30,1 \%(321), 4-2,4 \%(25)$; health groups: basic $81.5 \%(869)$, preparatory $4.9 \%$ (52), special medical 8.9\% (95), physical therapy 4.7\% (50); Schools: Construction $31.1 \%$ (332), Architecture and design 36.4\% (388), Transport structures 15.3\% (163), Economics and management in construction $9.9 \%$ (105), Construction technologies and engineering and environmental systems $7.3 \%(78)$;

- to the question «Do you attend physical education classes at the university?» $-89.9 \%$ (958) of them answered «yes», most of them were girls 56.7\% (605) and 33.2\% (353) - boys; $10.1 \%$ (108) - boys $5.9 \%$ (63), girls $4.2 \%$ (45);

- the question «Why do you attend physical education classes?»-43.8\% (467) answered «to get a credit» - boys $18.7 \%$ (199) and girls 25.1\% (268); «to maintain and develop physical fitness» $-39.5 \%$ (421) of them boys $18.7 \%$ (199) and girls $20.8 \%$ (222); «to switch the type of activity from intellectual to physical activity» $-16.7 \%$ (178) - boys $4.6 \%$ (49) and girls $12.1 \%$ (129), - most students go to physical education classes consciously with a specific purpose;

- to the question: «Do you like physical education classes at the university?»-34.2\% (365) answered «very interesting», of which 14.5\% (155) were girls and 19.7\% (210) were boys; $52.2 \%$ (556) answered «yes» - 19.3\% (206) and 32.8\% (350) were boys; $13.6 \%$ (145) answered «no» $-8 \%(85)$ of the were boys and $5.6 \%$ (60) were girls. As a result, $86.4 \%(921)$ of respondents like physical education classes at the university;

- to the question: «Do you participate in sports events held at the university?» - «yes» was answered by $12.4 \%$ (132) of students, including boys $8.3 \%$ (88) and girls $4.1 \%$ (44); «I try as much as possible» was answered by $16.8 \%(179)$ - boys $9.3 \%(99)$ and girls $7.5 \%(80)$; «no free time» for 33.2\% (354) - boys 10.8\% (115) and girls 22.4\% (239); answered «no» $37.6 \%$ (401) of them boys $13.3 \%$ (142) and girls $24.3 \%$ (259), a total of $29.2 \%$ (311) of students participate in university activities, but the majority of $70.8 \%(755)$ prefer studying;

- to the question: «Do you play sports in your free time?»-10.2\% (109) answered «no»boys $4.2 \%$ (45) and girls 6\% (64); «self - study» 51.3\% (547) - boys $17.3 \%$ (184) and girls $34 \%$ (364); «train in a fitness club, health center, swimming pool, etc.» $25.1 \%$ (267) - boys $7.5 \%$ (80) and girls $17.6 \%$ (187); «train in university teams» $13.4 \%$ (143) - boys $1.6 \%(17)$ and girls $11.8 \%$ (126), many students $89.8 \%$ (957) are engaged in sports, but due to quarantine (selfisolation), temporarily students were forced to switch to independent classes at home;

- to the question: «Is it possible to conduct physical education classes at the university remotely on a permanent basis?» - consider that «personal contact with the teacher is necessary» $19.5 \%$ (208) - boys 3.8\% (41) and girls $15.7 \%$ (167); agreed to use online studying «only during the quarantine period, in conditions of acute need» $44.9 \%$ (479) - boys $15.1 \%$ (161) and girls $29.8 \%$ (318); as a result, $64.4 \%$ (858) students would not like to engage in physical education remotely permanently, but $35.6 \%$ (379) of them boys $11.8 \%$ (126) and girls $23.7 \%$ (253) would do physical education remotely;

- to the question: «What physical problems occurred during the quarantine (selfisolation) in the process of distance learning?» - noted «deterioration of health» $3.3 \%(35)-$ 
boys $1.9 \%(20)$ and girls $1.4 \%(15)$; «there was an urgent need for movement, physical activity» $12.8 \%$ (137) - boys $4.7 \%(50)$ and girls $8.1 \%$ (87); «experienced psychoemotional stress» $23 \%(245)$ - boys $8.9 \%(95)$ and girls $14.1 \%(150)$; «there were all the above problems» $20.9 \%$ (223) - boys $5.7 \%(61)$ and girls $15.2 \%$ (162), as a result, $60 \%$ (640) of students had some health problems; $40 \%$ (426) did not have significant problems in the process of distance learning in self - isolation.

\section{Discussion}

The conducted research helped to determine strengths and weaknesses of the university's health-saving system using SWOT analysis (the development of chronic fatigue and burnout syndromes, not only among students of architecture in the learning process, but also among students of all Schools in the process of compulsory distance learning). Using the method of «Problem Solving and Decision-Making» (PSDM), possible solutions to these problems were established (we applied the practice of overcoming chronic fatigue syndrome and emotional burnout syndrome for students of all Schools in the process of distance learning). The conducted survey allowed us to establish positive statistics. The majority of full-time students consciously attend physical education classes to maintain physical fitness and to switch the type of activity from intellectual to physical, which in turn allows maintaining health (physical and mental) [20]. Due to the high workload at the technical university, many students do not participate in physical education events, and prefer to study. But at the same time they are actively engaged in sports on their own (at home, in the university's student sports club, fitness clubs, etc.). Also, this study revealed primary problems of students in the process of distance learning: the majority of respondents had health problems, increased psychoemotional stress on the background of inactivity, many students did not want to engage in physical education remotely on a permanent basis, preferred to use distance learning only in conditions of acute need [21].

\section{Conclusion}

It can be concluded that, after the experience of distance learning in isolation, the training of students will no longer be the same. That's why for the formation of a health-saving environment at the university, the following steps must be taken:

- To ensure the safety of the process of traditional training and distance learning compliance with the work and rest regime, limiting the periods of work at a personal computer, the use of a competent schedule and distribution of educational material in the course of classes;

- Use online technologies as a means of health saving during quarantine (pandemic), in isolation (separation of teachers and students' teams allows to prevent the possibility of infection spreading, ensuring safety and health preservation);

- Apply distance learning methods as a means of inclusive education - the opportunity to receive full educational services for students with temporary health disorders (seasonal diseases, various injuries, pregnancy, as well as students belonging to low-mobility groups of the population);

- Pay special attention to the study of health-saving technologies in the process of distance learning at advanced training courses for scientific and pedagogical workers;

- Combine models of the educational process, in which the traditional interaction of students and teachers, practical, scientific and social activities will be combined with the use of online courses, as well as with simultaneous learning in a distance format. 


\section{References}

1. R.A. Khuzhin, A.V. Greb. Physical education service contribution to technical university graduate's professional competitiveness, Theory and Practice of Physical Culture 4, 12 (2019).

2. D.M. Nasibullina, T.R. Nasibullin, N.A. Krasulina. Individual academic physical education programs for special health groups for physical progress, Theory and Practice of Physical Culture 4, 54-56 (2019).

3. N.K. Gafiatulina, L.I. Makadey, I.V. Gluzman, A.D. Lozhechkina, L.A. Volkova, A.P. Bandurin. The role of health-saving technologies in the process of students educational and professional socialization, EurAsian Journal of BioSciences 13 (2), 1557-1563 (2019).

4. V.I. Filonenko, M.A. Nikulina, E.V. Patrakov, O.P. Kovtun. Sotsiologicheskie Issledovaniya, Social representation about health and health preservation in young students 7, 152-157 (2018). DOI: 10.31857/S013216250000188-9.

5. E. Mugattarova, A. Bolotnikov, R. Garifullin, R. Imangulov, V. Kalmanovich, R. Khairullin. Development of health-saving environment at engineering university, IOP CONFERENCE SERIES Materials Science and Engineering 890, 012172 (2020). DOI: 10.1088/1757-899X/890/1/012172.

6. V. Panachev, L. Zelenin, A. Opletin, A. Legotkin, R. Kusekova. Aspects of healthimproving and sports-mass work students, Journal of Global Pharma Technology 10 (5), 268-273 (2018).

7. L. Akshayaa, V. Vishnupriya, R. Gayathri. Awareness of chronic fatigue syndrome among the college students - a survey, Drug Invention Today 11 (6), 1369-1371 (2019).

8. J. Shi, J. Shen, J. Xie, J. Zhi, Y. Xu. Chronic fatigue syndrome in Chinese middle-school students Medicine (United States) $97 \quad$ (4), 9716 (2018). DOI: 10/1097/MD.0000000000009716.

9. Yu.G. Nagornyak, T.A. Kanakina, V.A. Fokin. Study of syndrome of emotional burnout in students of the faculty of pharmacy, Health Care of the Russian Federation 62, 254258 (2018). DOI: 10.18821/0044-197X-2018-62-5-254-258.

10. S. Griggs. Hope and mental health in young adult college students: An integrative review, Journal of Psychosocial Nursing and Mental Health Services 55 (2), 28-35 (2017). DOI: 10.3928/02793695-20170210-04.

11. J. Breedvelt, Y. Amanvermez, M. Harrer, E. Karyotaki, S. Gilbody, C. Bockting, P. Cuijpers, D. Ebert. The effects of meditation, yoga, and mindfulness on depression, anxiety, and stress in tertiary education students. A meta-analysis Frontiers in Psychiatry 10 (APR), 193 (2019). DOI: 10.3389/fpsyt.2019.00193.

12. V.R. Kuchma, L.M. Sukhareva, I.K. Rapoport, E.I. Shubochkina, N.A. Skoblina, O.Yu. Milushkina, Gigiena i Sanitariya. Population health of children, risks to health and sanitary and epidemiological wellbeing of students: Problems, ways of solution and technology of the activity 96 (10), 990-995 (2017). DOI: 10.18821/0016-9900-2017-9610-990-995.

13. O. Kokun, Y. Imas, A. Vovkohon, V. Potop, G. Korobeynikov, L. Korobeynikova, A. Gorashchenco. Physical education and sports as a tool for formation of students' psychophysiological readiness to their professional work, Journal of Physical Education and Sport 18 (2), 966-971 (2018). DOI: 10.7752/jpes.2018.02143.

14. D.S. Savelyev, V.A. Kuvanov, E.S. Zherlygina. Implementation of the online format of training sessions on physical culture in the conditions of the university, Theory and Practice of Physical Culture 3, 15 (2021). 
15. T.N. Shutova, L.B. Andryushchenko, I.V. Orlan, N.V. Ryzhkin. Digital approach in the organization of physical culture and sports at the university, Theory and practice of Physical Culture 3, 12 (2021).

16. L.G. Pashchenko, O.S. Krasnikova. Influence of motor mode on physical health of university students, Theory and Practice of Physical Culture 6, 24-26 (2017).

17. B. Butzer, K. Ahmed, S.B.S. Khalsa. Yoga Enhances Positive Psychological States in Young Adult Musicians, Applied Psychophysiology Biofeedback 41 (2), 191-202 (2016). DOI: $10.1007 / \mathrm{s} 10484-015-9321-x$.

18. V.N. Irhin, I.V. Irhina, I.N. Nikulin. University sports and recreation activities system as a factor of ensuring the students health, World Journal of Medical Sciences 9 (3), 162-166 (2013). DOI: 10.5829/idosi.wjms.2013.9.3.1131.

19. N.G. Blinova, L.A. Varich, A. O. Poddubnyak. Health-Forming Lifestyle Aspects in Students of Various Higher Education Programs, Bulletin of Kemerovo State University 22 (1):115-122 (2020). DOI: 10.21603/2078-8975-2020-22-1-115-122.

20. T.H. Bailey, L.J. Phillips. The influence of motivation and adaptation on students' subjective well-being, meaning in life and academic performance, Higher Education Research and Development 35 (2), 201-216 (2016). DOI: 10.1080/07294360.2015. 1087474.

21. J.D. De Vries, M.L. van Hooff, S.A. Geurts, M.A. Kompier. Exercise as an Intervention to Reduce Study-Related Fatigue among University Students: A Two-Arm Parallel Randomized Controlled Trial, PloS one 11 (3), e0152137 (2016). DOI: 10.1371/ journal.pone.0152137. 